\title{
Studying the Carbon-Dioxide-Driven Freezing of Turkey Meat
}

\author{
Evgeny Nikolayevich Neverov \\ Department of Heating and Refregirating Engineering line \\ Kemerovo State University \\ Kemerovo, Russia \\ Yelena Valerievna Korotkaya \\ Department of Analytical Chemistry and Environmental \\ Science \\ Kemerovo State University \\ Kemerovo, Russia
}

\author{
Igor Alekseyevich Korotky \\ Department of Heating and Refregirating Engineering line \\ Kemerovo State University \\ Kemerovo, Russia \\ Aleksandr Nikolayevich Rasschepkin \\ Department of Heating and Refregirating Engineering line \\ Kemerovo State University \\ Kemerovo, Russia
}

\begin{abstract}
In recent years for refrigerated processing of poultry, development and introduction of different apparatuses operating on the principle of the direct contract with carbon dioxide have been conducted. The disadvantages of the used contact apparatuses operating using carbon dioxide are: relatively low output, increased consumption of $\mathrm{CO2}$, its insufficiently effective application. In the paper the construction and the principle of the apparatus operation for refrigerated processing of dead turkeys, the construction of which allows compensating these disadvantages, were presented. For the purpose of realisation of the developed apparatus in the industry, the specialists of Kemerovo State University at the Department of "Heating Venting Air Conditioning" developed an acting model of the apparatus and studied the modes of its operation. In the course of the apparatus operation, the time of refrigerating processing of turkey was determined; consumption of carbon dioxide with different masses of poultry and modes of the apparatus operation was defined. The proposed apparatus for refrigerated processing of poultry with carbon dioxide possesses improved productivity, provides a decrease in the consumption of carbon dioxide combined with its more effective application.
\end{abstract}

Keywords - apparatus, poultry, carbon dioxide, sublimation, temperature field, heat flux density, research, heat transfer coefficient, isotherms.

\section{INTRODUCTION}

Market surveys of meat production and con-sumption in Russia reveal that there is a significant growth in consumption of turkey meat; similar growth can be seen abroad. Growth of the consumer demand is grounded in features of this type of meat, such as: high taste qualities, increased energy value, balanced protein component, large diversity of bioactive substances, high availability of nutrients. Turkey meat is a dietary product, rich in vitamins of $\mathrm{A}$ and $\mathrm{B}$ groups and microelements; it also contains iodine, selenium, manganese and sulfur. It is important, that turkey meat is a white dietary meat, it has hypoallergic properties, it is a healthy food and as such, it is ideal for child nutrition. Percentage of meat in a single carcass of turkey is significantly higher than that of other agricultural birds and animals.

Turkey meat keeps its benefits during freezing, as the components do not lose their properties while stored. At that, storage life of marketable product increases significantly, which is important due to a comparatively high price of this type of meat, as it extends possibility for transportation, distribution and sales of this produce [7].

Currently, the industry applies the methods of turkey meat freezing, where air, precooled with various halons, is used as a cooling medium. These cooling methods have a number of drawbacks, such as: change in product appearance in contact method, a prolonged period of cooling, absorption of a significant amount of water by the carcasses. These negative factors lead to a loss of quality and shorten the storage life.

Recently, due to a need to develop relatively inexpensive and environmentally friendly food freezing methods that do not have the drawbacks of the traditional methods applied in meat freezing, there is an increased interest to cryogenic refrigeration of food products among the Russian food processing enterprises.

Among the methods of cryogenic cold treat-ment is freezing with carbon dioxide $[2,4,5]$.

In Russia and abroad, carbon dioxide finds more and more applications in food freezers. This is due to enactment of Montreal and Kyoto protocols aimed at environmental protection, discontinuation of production of R12, R 502 and some other cooling agents, and starting from 2020, also discontinuation of the R22 halon, which is widely applied in food transport systems.

Alcohol processing enterprises produce a large amount of carbon dioxide, which is then vented to atmosphere. Starting from 2020, Russian introduces a fee for CO2 venting to atmosphere for industrial enterprises. This measure shall make manufacturers think about processing or finding an application 
for carbon dioxide, thus allowing extension of technologies that use carbon dioxide as a working medium $[15,16]$.

Currently, carbon dioxide as a working medium for thermal processing of food products is not very commonly used, as energy costs for production of $\mathrm{CO}_{2}$ in the snowlike form are rather high and there is still no efficient recuperation technology. However, thanks to a number of its benefits, $\mathrm{CO}_{2}$ gains ever more currency, both as a cooling agent in closed systems and as a me-dium of direct application to the product surface (be it in solid or liquid phase) during the cooling treatment.

Food product freezing with carbon dioxide uses the technologies where $\mathrm{CO}_{2}$ directly contacts with the food product, leading to reduced duration of the process, preservation of product quality, minimal loss of product weight to drying without use of special packaging materials $[6,9,10]$.

Carbon dioxide may be used for contact freezing of virtually all food piece-goods. At that, $\mathrm{CO}_{2}$ has microbicidal properties, it is an efficient means for suppression of anaerobic bacteria propagation on product surface and reduces oxidation processes in the food products.

Thanks to that, application of carbon dioxide in direct contact freezers is promising, while some re-cent works in science and technology make it an inno-vative development $[11,12]$.

\section{MATERIALS AND METHODS.}

Figure 1 shows a diagram of an apparatus for cooling treatment of bird carcases with carbon dioxide, the design of this apparatus allows reducing $\mathrm{CO}_{2}$ consumption and is aimed at its maximum efficient application.

The apparatus has a fixed isolated body (1). Thermal insulation is installed between the casings of the body. On two sides of the apparatus, there are windows with flexible curtains in the cooled volume (14) and outside (13), which are used for supply and extraction of a conveyor. A flexible conveyor consists of a guide (2), along which bird carcasses (3) hanging from carriages (4) are moved with a chain drive (5).

To supply snowlike $\mathrm{CO}_{2}$ into the inner cavities of the carcasses, there is a number of dosing generators (9) on the shaft (6), which are supplied with liquid carbon dioxide through a pipeline (8); the flow is then constricted on orifice plates and the carbon dioxide is introduced inside the carcasses in the snowlike state. To circulate the gas medium, in the upper part of the chamber there are fans (10) driven by motors (11).

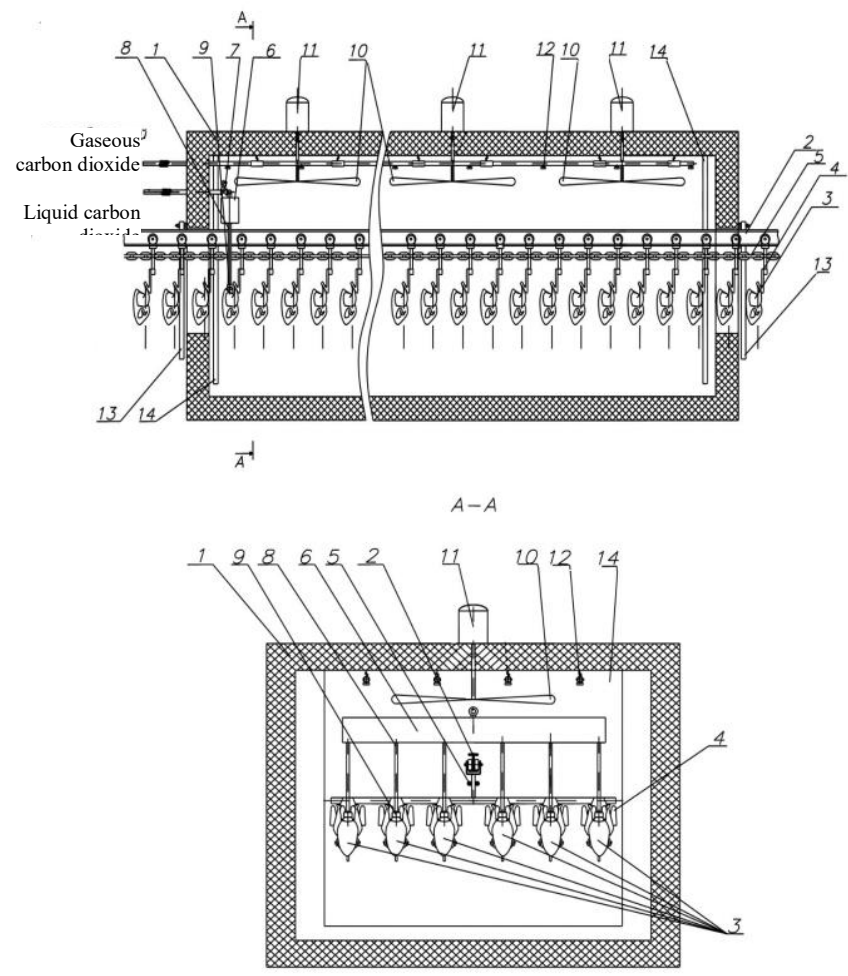

Fig. 1. The diagram of bird carcasses cooling treatment in the carbon dioxide medium

Eviscerated bird carcasses (3) are installed on carriages (4) and are moved along the guide (2) by the chain drive (5) through the flexible curtains $(14,13)$ into the chamber (1). When the bird carcasses are moving along the conveyor (2), they are registered with a photocell and the conveyor is stopped. This is when the liquid carbon dioxide is supplied through the solenoid valve (7) to the dosing generator, where it is transformed into the snowlike form and further supplied inside the bird carcass (6). Subsequently, the bird carcasses move along the conveyor (2) inside the chamber (1), getting frozen in the gaseous carbon dioxide medium that is supplied through a row of nozzles (12).

Fans (10) with motors (11) provide circulation of the gaseous medium inside the chamber. After passing the freezing zone with carbon dioxide supplied through the nozzles (12), the bird carcasses are withdrawn from the apparatus by the conveyor (2) through the flexible curtains $(13,14)[14]$.

A cascade cooling apparatus has been developed for carbon dioxide recuperation; the design of the apparatus is shown in Figure 2. 


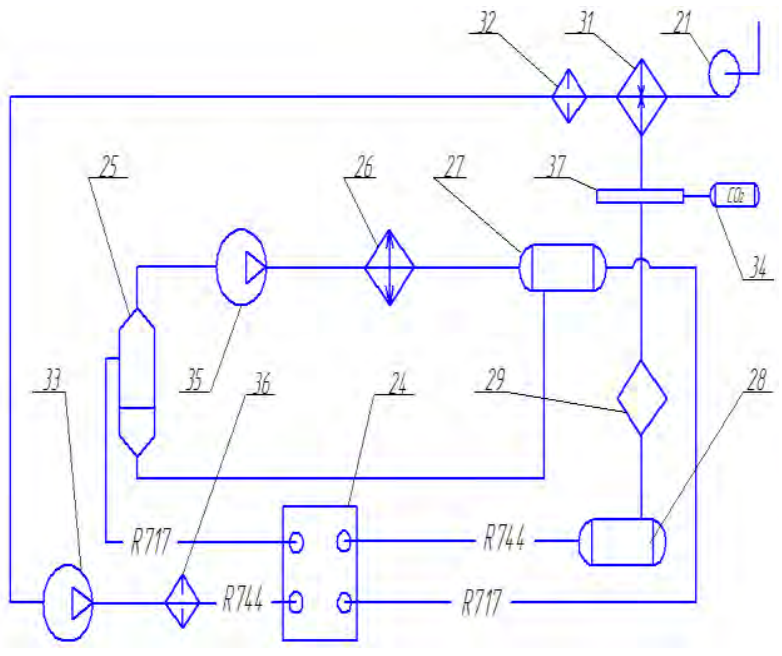

Fig. 2. A diagram of the cascade refrigerating plant

The cascade refrigerating plant operates in the following way: carbon dioxide is sucked from the chamber 31 through the manifold 19 and filter 32, compressed by a compressor 33 and through a dehydration filter 36 is supplied to the heat exchanger 24. After that, the liquid carbon dioxide arrives to the receiver 28 , intended for collection of the liquid carbon dioxide and surge control of the $\mathrm{CO}_{2}$ supplied to the apparatus. Then the non-condensible gases (air) are stripped in the air stripper. Through the manifold of the control station 37, the liquid $\mathrm{CO}_{2}$ including supply feed from a cylinder 34 , arrives to the apparatus 31 . The apparatus may be cooled with two systems that supply the carbon dioxide onto the tube side 10 and directly onto the product through the row of nozzles 6 . To remove the air from the apparatus after loading the product, the design provides a vacuum pump 21.

In the second cascade, the compressed gas from the compressor 35 is supplied to the air condenser 26, where ammonia vapors are cooled and condensed. The condensed liquid ammonia is poured into a line receiver 27 , intended for collection of liquid refrigerating medium and provision of its continuous supply into the evaporating system when heat load changes. After that, the refrigerating medium is supplied to a heat exchanger 24 , where as a result of heat exchange, the liquid ammonia is transformed into vapors and through the liquid separator 25 is sucked by the compressor [9;14].

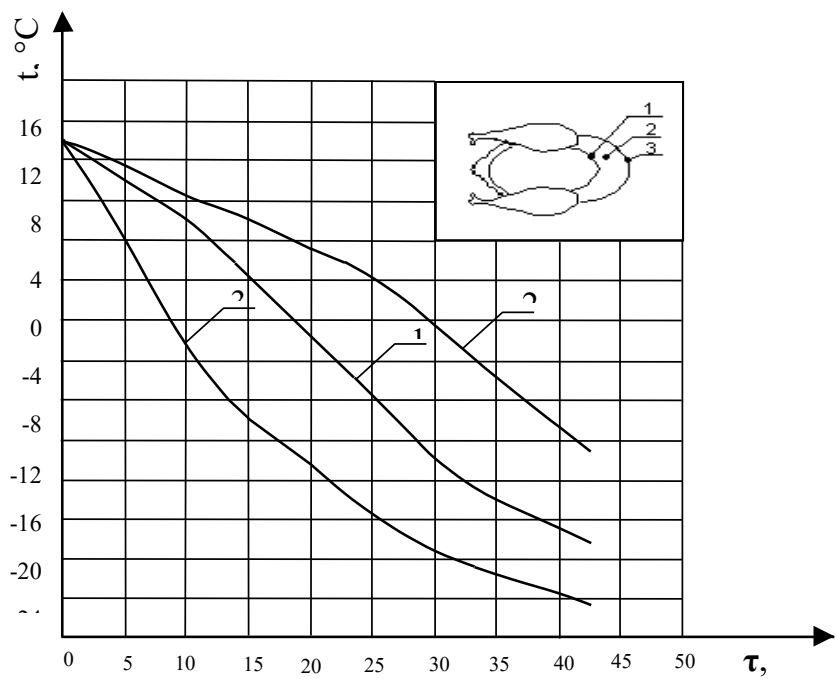

Fig. 3. Thermogram of the freezing process for a turkey carcass without air-gas medium circulation.
To implement this apparatus, specialists of the Kemerovo State University had developed a working model of the contact apparatus and completed a study of its operating modes.

The main task of these studies was to determine the duration of bird meat freezing in the carbon dioxide medium under various velocity of the air-and-gas medium inside the apparatus.

Control of the thermal field of a turkey carcass was performed with chromel-copel thermocouples connected to a measuring system. At the same time, measurements of the heat transfer rate from the external and internal surfaces of the carcass were performed with a special device for heat transfer rate measurement, model IPP-2. The air speed in the thermally insulated chamber was monitored with an electronic anemometer.

The experiments were conducted on unpackaged turkey carcasses weighing $1.9-2.0 \mathrm{~kg}$ and having the pectoral muscle thickness of $29 \pm 2 \mathrm{~mm}$, until the temperature in the central layer of the pectoral muscle reached $18{ }^{\circ} \mathrm{C}$.

During the research, a series of experiments were performed for various velocities of the air-gas medium movement: the first series was conducted without air circulation, the following series used the the air-gas velocity of $5 \mathrm{~m} / \mathrm{s}$ and $7 \mathrm{~m} / \mathrm{s}$. In all the experiments, a temperature of 65 ${ }^{\circ} \mathrm{C}$ below freezing was supported in the chamber.

\section{RESULTS AND DISCUSSION.}

The thermocouple layout and the thermogram of the bird carcass freezing without air-gas circulation is shown in Figure 3.

The duration of carcass freezing in this case amounted to 43 minutes. Analysis of the isotherms shows that the refrigeration process was intensive until the cryoscopic temperature was reached, after that a phase change from water to ice starts that releases latent heat of crystallization and, as a result, the rate of lowering the temperature decreases. After passing this part, the isoterms show the changes in carcass temperature after freezing the main volumes of water. Here, lowering of temperature is accelerated again.

In addition, in the thermogram (Fig. 3) one may observe, that freezing of the external layer of the carcass is more intensive than that of the internal layer; it is because the volume of snowlike carbon dioxide supplied into the internal cavity of the carcass is insufficient for intensive reduction of the internal layers temperature.

The heat transfer rate curve of the external surface (Fig. 4) shows that the maximum heat is removed in the initial moment when the temperature difference is maximal and $\mathrm{q}$ is equal to $3250 \mathrm{~W} / \mathrm{m}^{2}$. After that there is an abrupt drop in the heat transfer rate for 8 minutes due to lower surface temperature. Then, $\mathrm{q}$ stabilizes and after reaching the temperature of minus $18{ }^{\circ} \mathrm{C}$ in the center of the pectoral muscle, it approaches $1000 \mathrm{~W} / \mathrm{m}^{2}$.

All the while, mean integrated value of the heat transfer coefficient from the external surface is $16 \mathrm{~W} /\left(\mathrm{m}^{2} \mathrm{~K}\right)$. 
In this case, maximum value of the heat transfer rate from the inner surface of the carcass is $1250 \mathrm{~W} / \mathrm{m}^{2}$, while the mean integrated value of the heat transfer coefficient decreases to $6.7 \mathrm{~W} /\left(\mathrm{m}^{2} \mathrm{~K}\right)$.

The carcass freezing time with the speed of the air-gas medium of $5 \mathrm{~m} / \mathrm{s}$ amounted to 25 minutes (Fig. 5).

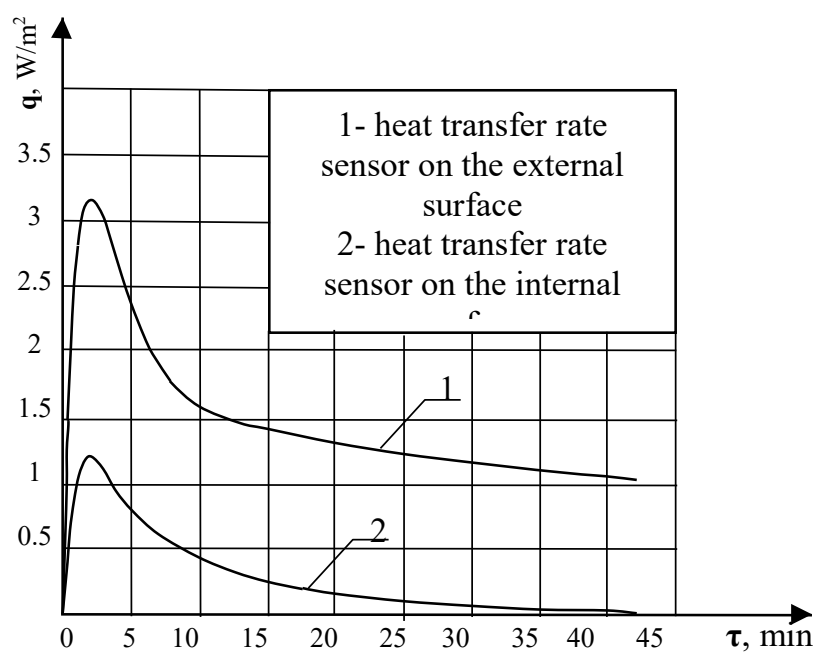

Fig. 4. Heat transfer rate during refrigeration of turkey carcass without air circulation

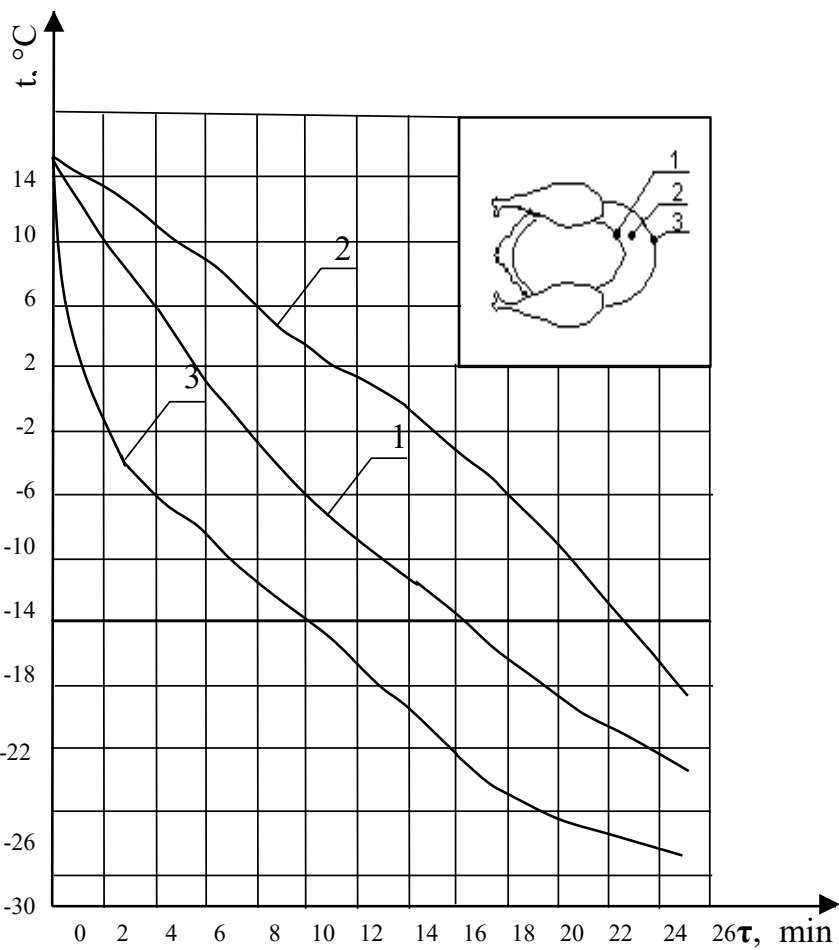

Fig. 5. Thermogram of the freezing process for a turkey carcass with air-gas medium circulation at $5 \mathrm{~m} / \mathrm{s}$
Analyzing the curves obtained, one may conclude that more intensive drop in temperature takes place in the external layers of the carcass due to heat removal with gaseous $\mathrm{CO}_{2}$, despite the fact that inside the carcass cavities the $\mathrm{CO}_{2}$ is in the snowlike form and its specific heat is higher than that of gas. This may be explained by a part of the snowlike carbon

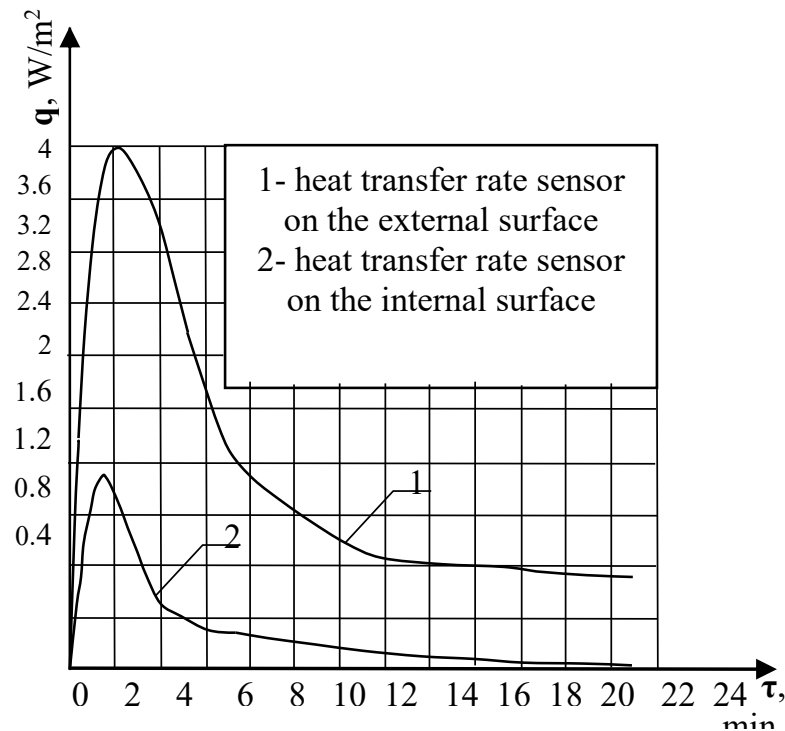

Fig. 6. Heat transfer rate during freezing a turkey carcass with circulation of the air-gas medium at $5 \mathrm{~m} / \mathrm{s}$

dioxide in the inner cavities of the carcass undergoing active sublimation in the initial period of time due to a large temperature difference and forming a gaseous layer between the skeleton of the carcass and the refrigerating medium. It increases the thermal resistance; also, the air inside this layer is not agitated. External layers are subject to forced convection of the air-gas medium leading to a more intensive heat exchange and a higher value of heat removed in the initial moment of the cooling treatment, unlike in the previous experiment without circulation. Kinetics of the heat removal (Fig. 6) is an evidence of the same. Thus, despite the sublimation temperature for the snowlike $\mathrm{CO}_{2}$ is at the level of minus $78{ }^{\circ} \mathrm{C}$, the mean integral value of $\mathrm{q}$ from the internal surface in this case is $360 \mathrm{~W} / \mathrm{m}^{2}$, and mean integral value of the heat exchange coefficient from the internal surface of the bird carcass is $8.2 \mathrm{~W} /\left(\mathrm{m}^{2} \mathrm{~K}\right)$. At that, for the external surface, the mean integrated value of the heat transfer rate is $900 \mathrm{~W} / \mathrm{m}^{2}$ and mean integrated value of the heat exchange coefficient is $19.6 \mathrm{~W} /\left(\mathrm{m}^{2} \mathrm{~K}\right)$.

With further increase in the speed of movement of the airgas medium, the trend for shorter freezing time continued. So, we determined, that with the speed of $7 \mathrm{~m} / \mathrm{s}$, the freezing time amounted to $20 \mathrm{~min}$. The value of the maximum heat transfer rate from the external and internal surfaces amounted to 5000 $\mathrm{W} / \mathrm{m} 2$ and $2000 \mathrm{~W} / \mathrm{m} 2$ respectively, while the mean integral value of the heat exchange coefficient was $20.2 \mathrm{~W} /\left(\mathrm{m}^{2} \mathrm{~K}\right)$ for the external surface and $9.3 \mathrm{~W} /\left(\mathrm{m}^{2} \mathrm{~K}\right)$ for the internal one.

Basing on the results of the research conducted, a nomographic chart has been developed (Fig. 7) that allows 
determining the cooling treatment duration from known speed of the air-gas medium circulation and target temperature of a turkey carcass. It allows optimizing the carbon dioxide costs in cooling treatment of turkey carcasses in contact freezers by changing the nominal target temperature of the carcass [7].

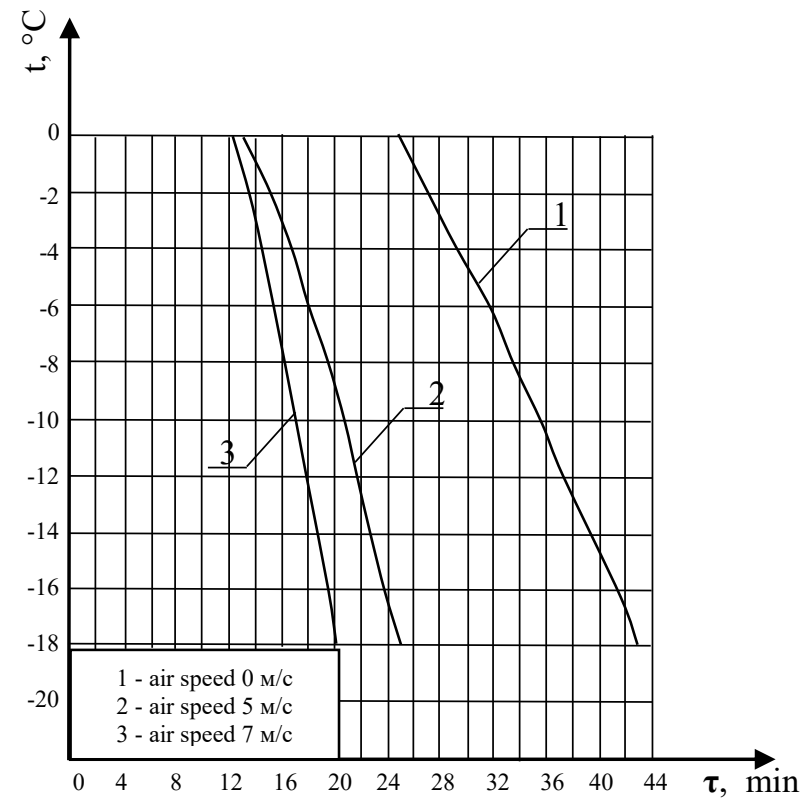

Fig. 7. Nomographic chart of poultry freezing with carbon dioxide

In this nomographic chart, along the $\mathrm{x}$ axis there is a cooling treatment time for turkey meat in minutes. Along the $y$ axis, there is a temperature inside the turkey carcass in ${ }^{\circ} \mathrm{C}$. In the working area of the nomographic chart there are thermal isotherms of turkey meat freezing for the speed of the air-gas medium circulation inside the chamber of $0 ; 5$ and $7 \mathrm{~m} / \mathrm{s}$.

To determine the duration of the turkey carcass cooling treatment one needs: to take the target temperature along the y axis, draw a line perpendicular to the y axis until reaching the freezing isotherm for a given speed of circulation in the chamber, $0 ; 5$ or $7 \mathrm{~m} / \mathrm{s}$, then draw a line perpendicular to the $\mathrm{x}$ axis and find the duration of the cooling treatment.

\section{CONCLUSIONS}

Consequently, application of air-gas medium circulation to freezing of turkey carcasses allows shortening the cooling treatment and reducing carbon dioxide consumption.

However, when selecting a speed of air-gas medium circulation, one shall bear in mind that with increased air circulation speed, energy costs for fans increase as well.

\section{References}

[1] A.A. Antonov "Classification of food in order to unify the calculations of refrigeration equipment”, Meat industry, 2002, No. 5, pp. 45-46.
[2] A.B. Baranenko, G.A. Belozerov, O.M. Tagantsev et al "State and prospects of development of refrigerating branch of Russia. Refrigerating equipment", 2009, No. 3, pp. 20-24.

[3] G.A. Belozerov, M.A. Dibirasulayev, V.N. Koreshkov, V.S Kolodyaznaya, O.N. Rumyantseva, D.A. Baranenko "Modern technologies and equipment for cooling treatment and storage of foodstuff, Refrigerating equipment", 2009, No. 4, pp. 18-22.

[4] G.A.Belozerov, S.P. Andreev "Functioning cold-chain - quality assurance of food in the consumer market of Russia", Meat a number, 2014, No. 2, pp. 78-84.

[5] O.V. Bolshakov "Russian industry and science: modern refrigeration technology and addressing healthy food”, Kholodilnaya Tekhnika, 2002, № 5, pp. 4-6.

[6] O.N. Brawlers, A.A. Gorokhov, E.N. Neverov "Issledovaniye of operation of the generator - the batcher of snegoobrazny carbon dioxide, the Messenger of the International academy of cold", 2005, No. 4, pp. 20-21.

[7] GOST 31473-2012 Turkey Meat (carcasses and their part), General technical conditions, Moscow: Standardinform publishing House, 2013.

[8] L. Dyshlyuk "Modernization of the experimental technological line for the production of enzyme hydrolysates of down and feather raw material. Journal of Industrial Pollution Control", Vol. 33 (1), 2017, pp. 816-823.

[9] E.N. Neverov "Apparat for cooling treatment of foodstuff with recirculation of carbon dioxide", Herald of the International academy of cold, 2016, No. 1, pp. 60-65.

[10] E.N. Neverov, S.N. Nechayev, I.A. Petrov "Determination of amount of carbon dioxide for cooling treatment of carcasses of a bird", Progressive technologies and the prospects of development, Proc. of int. sci. and practical conference, Tambov, 2010, pp. 150-152.

[11] E.N. Neverov "Use of carbon dioxide for cooling treatment of carcasses of a bird", Technician and technology of food productions, 2015, No. 4, pp. 111-115.

[12] E.N. Neverov, O.N. Buyanov, A.N. Grinyuk "Application of packing when cooling broilers with carbon dioxide", Technician and technology of food productions, 2014, No. 2, pp. 15-19.

[13] A.M. Popov, D.V. Donia, K.B. Plotnikov "Determination of dependence between thermophysical properties and structural-and-phase characteristics of moist materials", Foods and raw materials, 2017, Vol. 5, No. 1, pp. 137-143.

[14] O.N. Buyaknov, E.N. Neverov, S.N. Nechayev "The device for cooling treatment of carcasses of a bird carbon dioxide", Pat. of the Russian Federation No. 2453779, MPK F25D 3/12 F25D 13/00.

[15] D.M. Hovalyg, M. Sinitsyna, A.V. Baranenko, A.P. Tsoi "Energoeffektivnost and ecological safety of the equipment of low temperatures", NIU ITMO Scientific magazine. Series: Refrigerating equipment and conditioning, 2014, No. 1, pp. 2-6.

[16] V.N. Tselikov "O implementation of the obligations of the Russian Federation following from the Vienna convention on protection of an ozone layer and the Monrealskly protocol on the substances destroying an ozone layer", Refrigerating business, 2003, No. 3, pp. 26-31.

[17] P.S. Hrnjak, C.Y. Park "In tube heat transfer and pressure drop characteristics of pure $\mathrm{NH}_{3}$ and $\mathrm{CO}_{2}$ in refrigeration systems", IIR Conference: Ammonia Refrigerating Technology for Today and Tomorrow, Ohrid, 2007, pp. 48-53. 